\title{
OS GERAIZEIROS E OS USOS DO TERRITÓRIO E A SOCIOBIODIVERSIDADE EM BURITIZEIRO-MG
}

\author{
Jaqueline Borges Inácio \\ Doutoranda pelo Programa de Pós-Graduação em Geografia-UFU \\ jaquelinebinacio@yahoo.com.br \\ Rosselvelt José Santos \\ Professor Doutor Titular do Instituto de Geografia-UFU \\ rosselvelt@ufu.br
}

\begin{abstract}
RESUMO
O objetivo deste trabalho é analisar como ocorre nos lugares os diferentes usos do território no município de Buritizeiro na área delimitada para implantação da Reserva Extrativista Serra do Alemão. Ao tratarmos de processos amplos discutimos a importância da sociobiodiversidade do Cerrado na região Norte de Minas Gerais, principalmente em espaços comunitários. As informações foram obtidas a partir de trabalho de campo em duas comunidades rurais que estão situadas na área delimitada. Nas comunidades Gerais do Calixto e Lança 1 dialogamos demoradamente com os sujeitos locais obtendo descrições detalhadas das suas práticas sociais, das paisagens, dos seus modos de vida, de suas lutas e mobilizações para se manterem como populações tradicionais e extrativistas. A luta em defesa do território foi narrada como repleta de estratégias sociais para permanecerem dilatando suas experiências. O uso do território requisitado a ser RESEX pelos geraizeiros, além de ser uma forma de resistência é nos lugares que eles criam e também recriam ciências sobre formas, conteúdos e estruturas sociais objetivando garantir a vida em suas várias dimensões.
\end{abstract}

Palavras-chave: Sociobiodiversidade. Cerrado. RESEX. Geraizeiros.

\section{THE “GERAIZEIROS”, TERRITORY USAGES AND SOCIOBIODIVERSITY IN BURITIZEIROS-MG}

\begin{abstract}
This work aims to analyze how it occurs in the places, the distincts territory usages in Buritizerio municipality within an area set aside to stablish an extraction reserve called "Reserva Extrativista Serra do Alemão". When dealing with broad processes we discuss Cerrado sociobiodiversity in the northern region of Minas Gerais state, mainly in community spaces. We gathered information from field work in two rural communities located in the delimited area. We had long conversations with local dwellers in the communities called "Gerais do Calixto" and "Lança 1", in which we obtained detailed descriptions of their social practices, landscapes, ways of life, their struggles and mobilizations to keep themselves as traditional and extractive people. The struggle for their territory - as narrated, is full of social strategies to keep them expanding their experiences. The usage of the "RESEX" territory for "Geraizeiros", besides being a resistence form is also in the places where they create and re-create sciences about forms, contents and social structures in order to make a living in its various dimensions.
\end{abstract}

Key words: Sociobiodiversity. Cerrado. RESEX. Geraizeiros.

\section{INTRODUÇÃO}

O uso do território analisado a partir da sociobiodiversidade faz comparecer em Buritizeiro, comunidades tradicionais, que na área delimitada, denominada como Reserva Extrativista Serra do Alemão, indica várias complexidades sociais. Elas se vinculam aos lugares como processos decorrentes de práticas

\footnotetext{
1 Este trabalho faz parte dos resultados do projeto: Sociobiodiversidade do Cerrado do projeto de pesquisa: Desenvolvimento Territorial e Sociobiodiversidade: perspectivas para o mundo do Cerrado/4611 - Programa de Apoio à Pós-Graduação e à Pesquisa Científica e Tecnológica em Desenvolvimento Socioeconômico no Brasil (PGPSE/CAPES).
} 
humanas relacionadas ao uso do Bioma Cerrado. Sua importância nos contextos social, cultural, econômico e político do Norte de Minas Gerais podem ser pensados como resistência.

Os geraizeiros ${ }^{2}$ presentes no Cerrado desde o século XIX, na região norte mineira, fazem uso do território pesquisado antes do município de Buritizeiro ser emancipado no ano de 1963. O campo começou a ser modernizado pelas tecnologias de produção aplicadas pela Revolução Verde, na década de 1960. Desde então, eles fixaram-se no lugar fazendo comparecer os seus vínculos territoriais. Eles estabeleceram suas relações sociais criando lugares de vida. As famílias delimitaram os seus pedaços de chão, os quais consistem em relações de afetividade, estabelecimento de territorialidades, que estão para além da lógica da propriedade privada e dos processos de reprodução capitalista.

As comunidades tradicionais representadas pelos geraizeiros, usavam a terra de maneira a promover sustentabilidade. Trabalhavam em seus domínios apenas para o sustento de sua família. Praticamente viviam da coleta de frutos do Cerrado, e também cultivavam alguns alimentos como: arroz, mandioca, feijão. Galinhas, porcos e vacas leiteiras eram criações que completavam suas práticas sociais fundamentadas na lógica da fartura. Trabalhavam para não faltar o de comer. No caso da criação do gado leiteiro o objetivo era garantir a produção de queijo e requeijão artesanal e alguma renda em dinheiro.

Em 1970, o território antes utilizado apenas para obtenção dos meios de vida começou a ser lugar de conflitos e disputas por parte do agronegócio. A presença e atuação (re) produtivista do capital foi sendo sentida na paisagem, pois reocupada por grandes empresas, fez surgir imensas plantações de eucalipto, enclausurando aqueles que tinham história nos lugares. Desse modo, parte das terras do Cerrado em Buritizeiro passaram a ser devastadas. As espécies nativas foram sendo derrubadas, dando lugar as atividades de silvicultura.

O plantio e cultivo do eucalipto teve incentivos de uma política de Estado na década de 1970 que implicou no arrendamento de terras tidas como desocupadas a empresas plantadoras de eucalipto. A inserção dessa monocultura na região Norte de Minas, especificamente em Buritizeiro provocou severas alterações no meio ambiente, como a perda de biodiversidade e a escassez de água. (NOGUEIRA, 2009).

Cultura perene praticada a partir de grandes investimentos de capital, originalmente, foi cultivada para abastecer as carvoarias, as fábricas de cimento e as siderúrgicas dos municípios vizinhos: Pirapora e Várzea da Palma.

Segundo Gama (2006):

O município teve grande parte de seu território desmatado para abrigar esta nova forma de exploração capitalista. Nesse processo, expressiva parcela de camponeses que habitava as áreas rurais do município foi expulsa de suas terras, uma vez que ocupavam áreas devolutas concedidas pelo Estado a grupos empresariais, que tiveram suas atividades financiadas pelo Banco do Nordeste, o que comprova a política concentradora do Estado. (GAMA, 2006, p.43).

Essa situação de reocupação territorial pode ser pensada a partir das reflexões de Heidrich (2008, p.273). $\mathrm{O}$ autor afirma que "as territorialidades conflitantes, podem referir-se ao mesmo objeto, ao uso ou à expectativa de uso, não exatamente por áreas delimitadas, mas, por espaços representados, vividos e seus usos".

Contudo, no contexto do município de Buritizeiro, destacam-se formas de resistências envolvendo os geraizeiros. Esse grupo humano usa o território, mesmo que essas áreas não sejam propriedades privadas deles. Como não proprietários, se enquadram na condição de posseiros. Ao usarem o bioma Cerrado naquilo que lhes permitir obter os meios de vida, eles desenvolvem práticas sociais de oposição as tensões a partir da experiência que se torna conhecimento, habilidade, jeitos de viver.

\footnotetext{
2 Geraizeiros são as populações que habitam os campos gerais do Norte do estado de Minas Gerais. Se autodefinem em contraposição a outros povos (catingueiros, vazanteiros e veredeiros) que, apesar de se situarem nas mesmas regiões geográficas, vivem em biomas e com modos de vida distintos. São conhecidos como geraizeiros, geralistas ou chapadeiros. Seu modo de vida é completamente alinhado às características do Cerrado, de onde tiram tudo o que é necessário para sobreviver. Atuam de forma diversificada na produção dos meios de vida, por meio da criação de animais, plantações e extrativismo. (CNPCT - Comissão Nacional de Desenvolvimento Sustentável dos Povos e Comunidades Tradicionais-Portal Ypadê- Ministério do Meio Ambiente, 2016).
} 
A vida prática tornado modo de vida gera conhecimentos. Impulsiona domínios de saberes e fazeres adquiridos ao longo de relações com o bioma nas singularidades dos lugares. Seus modos de ver a vida indicam ancestralidades que são dinamizados na prática cotidiana fazendo surgir e também redefinir territorialidades.

Para Heidrich (2008):

Algumas territorialidades presentes nestas situações se referem a formas tradicionais de uso da terra e de reprodução social, mas também se encontram usos pertinentes a demandas da reprodução capitalista hegemônica, as quais destoam das compreensões socioculturais locais. (HEIDRICH, 2008, p.272).

Contudo, a área demarcada ainda não foi reconhecida. A demarcação é uma proposição dos sujeitos que vivem nas comunidades. Assim, mesmo antes da implantação da RESEX, a área apresenta diferentes usos e apropriações, proporcionando diversos conflitos e tensões. A personificação das disputas vem sendo possível a partir de alguns sujeitos. Os geraizeiros que vivem nos lugares mantem o Cerrado "de pé”, condição para extraírem os frutos das árvores e promoverem o autossustento da família. A monocultura de eucalipto derruba o Cerrado, cultiva madeira para abastecer as carvoarias e os "atravessadores" representados por aqueles que não são e não estão no lugar.

Os outsiders que não se caracterizam como extrativistas e geraizeiros, interferem no uso do território e isso, prejudica a existência e a permanência desses sujeitos no lugar, uma vez, que aqueles que não são, estão se apropriando do espaço daqueles que são do lugar (geraizeiros), pensando meramente na lucratividade que esses frutos trarão no momento em que são comercializados no mercado.

Sem contar que esses sujeitos não compreendem ou não possuem conhecimento, em relação aos ciclos da natureza, para que possam adentrar o território e extrair apenas o necessário para atender as demandas da família. Além disso, esses sujeitos, coletam os frutos do Cerrado fora de sua época produtiva e vendem por preços diferentes daqueles praticados pelos geraizeiros que são do lugar.

Segundo Heidrich (2008):

Desta forma, não é unicamente certa área em poder de alguém o fator da territorialidade. A relação que a cria nem sempre necessita do sinal da demarcação. É o que se observa nas implicações decorrentes da implantação das UCs. As relações que aproximam e vinculam pessoas, famílias ou instituições são também ocupações, usos, sentimentos, cotidianos, percepções, representações, etc. (HEIDRICH, 2088, p. 273).

Pertencer e "ser" do lugar inclui reconhecer que há um vínculo de afetividade com o lugar. Este sentimento é transmitido na emoção que o sujeito demonstra ao se referir e definir o que este lugar representa de fato para sua existência. Estes fatores fazem com que os geraizeiros permaneçam e lutem cotidianamente para permanecerem na área pretendida a se tornar RESEX, mesmo que as situações se mostrem desfavoráveis a sua condição de existência no lugar. (INÁCIO, 2014).

A saída que esses sujeitos encontraram para permanecerem no lugar, é cultivar a terra com plantações de mandioca, abacaxi, hortaliças e criação de animais de pequeno porte voltados para a alimentação como galinhas. Além disso, eles continuam coletando os frutos do Cerrado, de acordo com os seus ciclos. Assim, os geraizeiros extraem da natureza o seu autossustento, onde comercializam os produtos derivados de seus cultivos e das espécies do Cerrado.

Tratam-se de 30 famílias que vivem nas comunidades rurais que estão dentro da área da RESEX, possuem moradias na cidade também, pois, foi uma maneira que encontraram de seus filhos frequentarem a escola, considerando que a distância entre o rural e o urbano é de aproximadamente 34 quilômetros, e de que nas comunidades não existem unidades escolares e tão pouco transportes.

Sendo assim, alguns desses sujeitos permanecem a maior parte do tempo no meio rural, trabalhando na terra, conservando seus modos de vida e seus saberes e fazeres, uma forma de resistirem e garantirem sua permanência no lugar, mesmo que a Reserva Extrativista Serra do Alemão ainda não tenha sido implementada. E vão para suas casas na cidade nos finais de semana, enquanto outros residem no urbano com seus filhos e vão as comunidades de uma a três vezes por semana.

O trabalho desenvolvido pelos geraizeiros é realizado de forma comunitária, onde pudemos observar, no momento em que estivemos no campo, que existem relações de parentesco, de compadrio e de vizinhança, onde eles possuem vínculos territoriais no lugar. 
As relações são singulares, pois à medida que não passam simplesmente pela lógica dominante (agronegócio e Estado), indica que aqueles sujeitos vão permanecendo no lugar, na luta pela existência, que se dá por meio da experiência adquirida no cotidiano. Apoderar-se do conhecimento decorre das suas relações com o Cerrado. Nesse processo apreender os ciclos da natureza desenvolvendo consciência coletiva em relação a preservação do Bioma Cerrado Ihes possibilitam afirmação, confiança de continuarem retirando da natureza o necessário para a vida deles.

\section{METODOLOGIA}

Para atingir os objetivos da pesquisa que aqui nutriu as nossas reflexões, estabelecemos uma abordagem pautada nos usos do território e naquilo que os usos representam para afirmação das comunidades tradicionais. Nesse caminho exploramos e comparamos teoricamente as categorias vínculos territoriais e territorialidades. Nos lugares dialogamos com os sujeitos envolvidos no processo de reinvindicação de um território geraizeiro, o qual se anuncia a partir das práticas sociais daqueles sujeitos, a medida em que lutam pelo reconhecimento do seu território. Identidade e pertencimento foram analisados a partir da rexistência relativa e relacional à experiência dos sujeitos que participam do movimento.

A partir dos trabalhos de campo, os modos de vida, costumes, hábitos e tradições foram sendo conhecidos, indicando que a maioria dos sujeitos que vivem na área reivindicada a se tornar RESEX estabelece relações com o Cerrado referenciada em saberes e fazeres constituídos histórico e culturalmente. A criação de vínculos territoriais com o lugar foi estudada considerando as estratégias de permanência comunitária.

Além disso, para subsidiar a reflexão teórico empírica, consultamos uma bibliografia especifica sobre as populações tradicionais do Cerrado. Os sites de órgãos governamentais vinculados ao meio ambiente foram importantes na geração de informações referentes ao Bioma Cerrado, a implementação das Unidades de Conservação de Uso Sustentável e legislações que garantem às populações tradicionais uma existência equilibrada e objetivada nas demandas das famílias.

Destacamos as incursões ao campo em duas das comunidades rurais que estão situadas na área relacionada a RESEX Serra do Alemão. Estabelecemos observação, descrição e problematização das comunidades Gerais do Calixto e Lança 1, tendo como motivação as mudanças na paisagem geográfica dos lugares e seus entornos. Nas casas residenciais dialogamos com os sujeitos do local, abordando temas que identificamos como principais. A motivação para falarmos sobre os temas foram os eventos socioambientais e suas consequências para a vida comunitária e suas atividades. Nas falas sobre o histórico de lutas exploramos as memórias sobre os seus modos de vida, mobilizações para se manterem como populações tradicionais e extrativistas.

Nos diálogos sobre o tema uso do Cerrado procuramos deixar que os sujeitos ficassem à vontade para expressar por meio de suas práticas sociais o que o Cerrado representa para eles e quais as motivações que fazem com que eles permaneçam no lugar. Com relação aos conflitos e tensões procuramos dialogar explorando os diferentes usos e apropriações do território em questão.

\section{RESULTADOS E DISCUSSÃO}

O município de Buritizeiro localiza-se na mesorregião Norte de Minas Gerais (Figura 1). A sua área territorial é de $7.218,401 \mathrm{~km}^{2}$, sendo considerado um dos maiores municípios da região.

Em 2019 a população estimada era de aproximadamente 28.000 habitantes, com densidade demográfica de $3,73 \mathrm{hab} . / \mathrm{km}^{2}$. É uma região de transição de clima tropical semiúmido para o semiárido, com regime pluviométrico marcado por duas estações definidas (úmida e seca). A vegetação predominante no município é o Cerrado que são consideradas como gerais. (Figura 2).

Segundo Nogueira (2009):

Gerais é a denominação no Norte de Minas Gerais, dada pela gente local aos topos de serra, planaltos, encostas e vales dominados por Cerrado. É também o território reivindicado e um dos mais importantes vetores no processo de afirmação identitária dos Geraizeiros, oferecendo elementos discursivos e perfomativos de justificação para as demandas desse grupo, numa ampla arena de articulação política. Isso porque os Geraizeiros também estão situados em contextos diversos e em relação a outros atores sociais. (NOGUEIRA, 2009, p.23). 
Figura1 - Buritizeiro (MG): localização do município em Minas Gerais, 2020

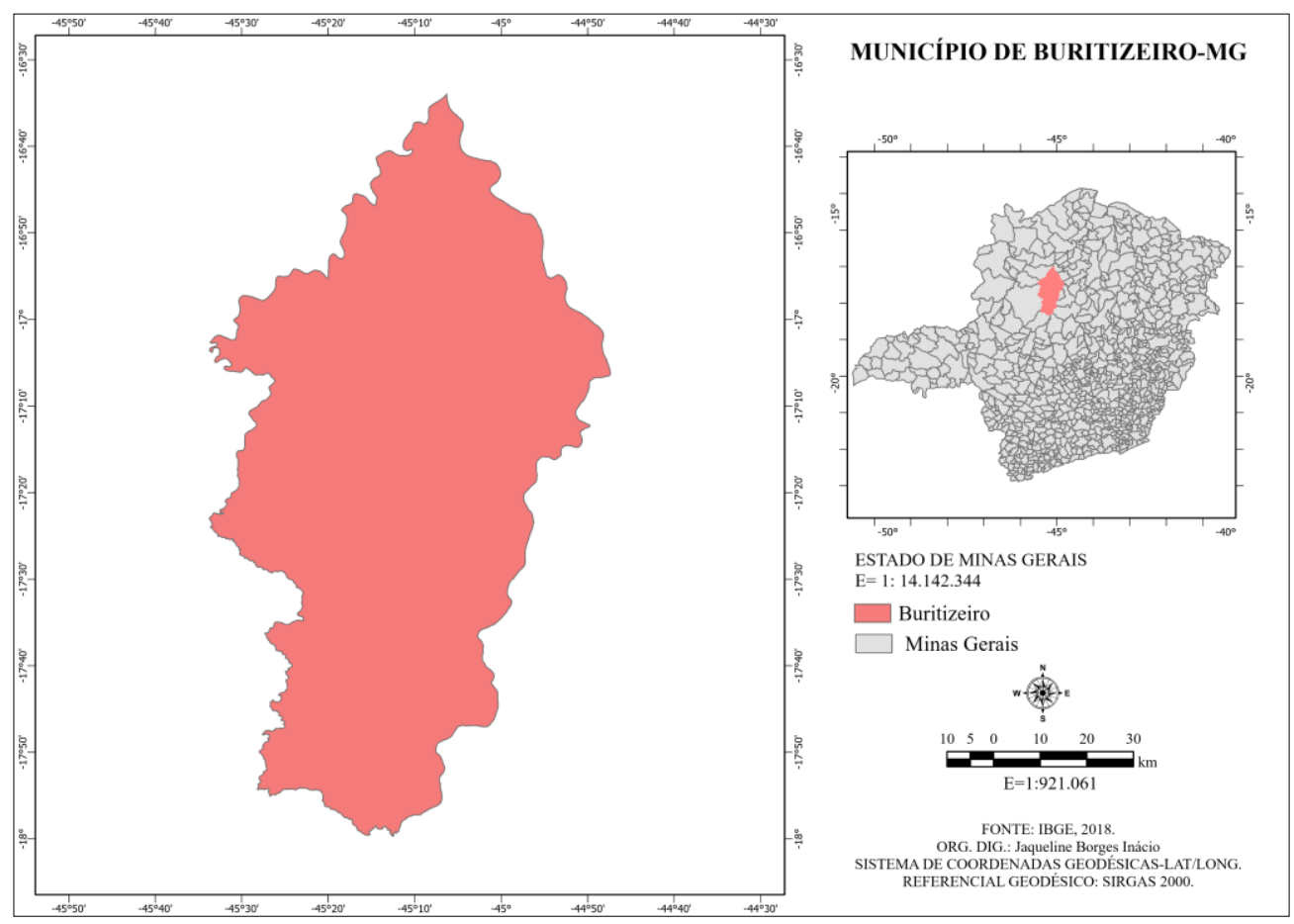

Fonte: IBGE, 2018. Organizado e digitalizado por: INÁCIO, J.B. (2020).

Figura 2 - Buritizeiro (MG). Vegetação de Cerrado (Gerais), 2019

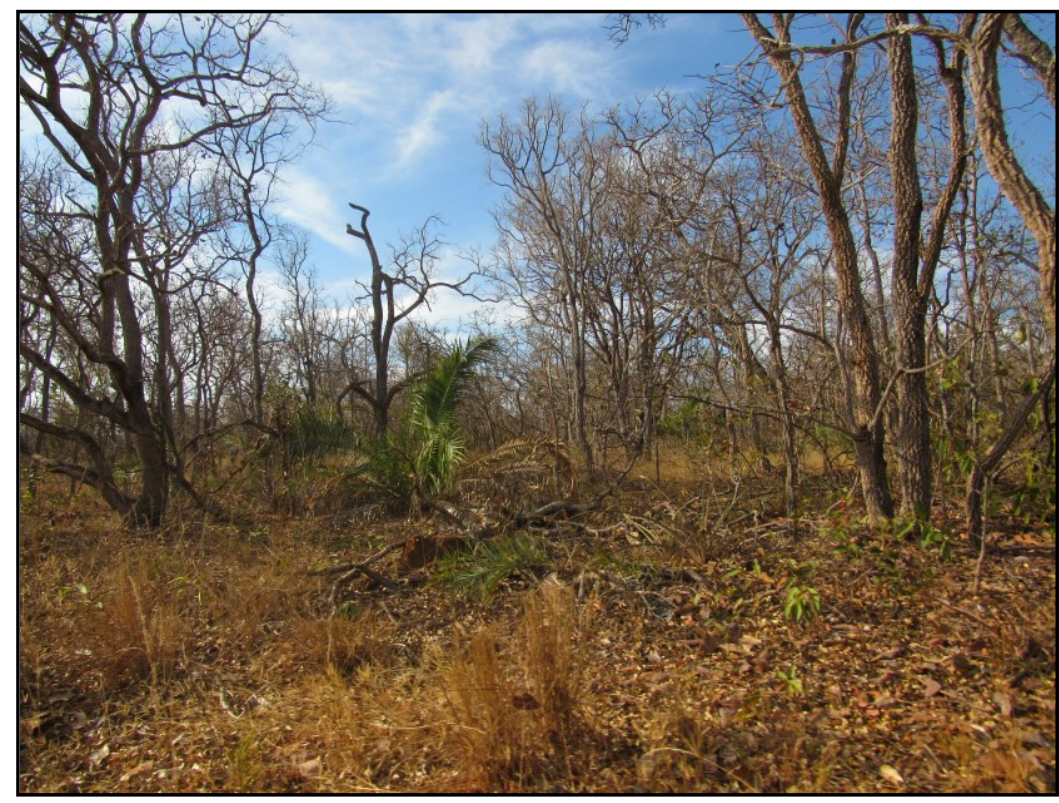

Fonte: INÁCIO, J.B; SANTOS, R.J (2019).

Cabe destacar que na área delimitada para a implantação da RESEX Serra do Alemão, onde estão localizadas as comunidades tradicionais geraizeiras há uma área de vereda, onde encontram-se os buritis que são uma espécie de palmeira, e sua ocorrência se dá em menor densidade comparada a um palmeiral (Figura 3). A vereda é cercada por um estrato arbustivo herbáceo característico. (EMBRAPA, 2020). 
Figura 3 - Buritizeiro (MG): área de vereda-buritizal, 2019

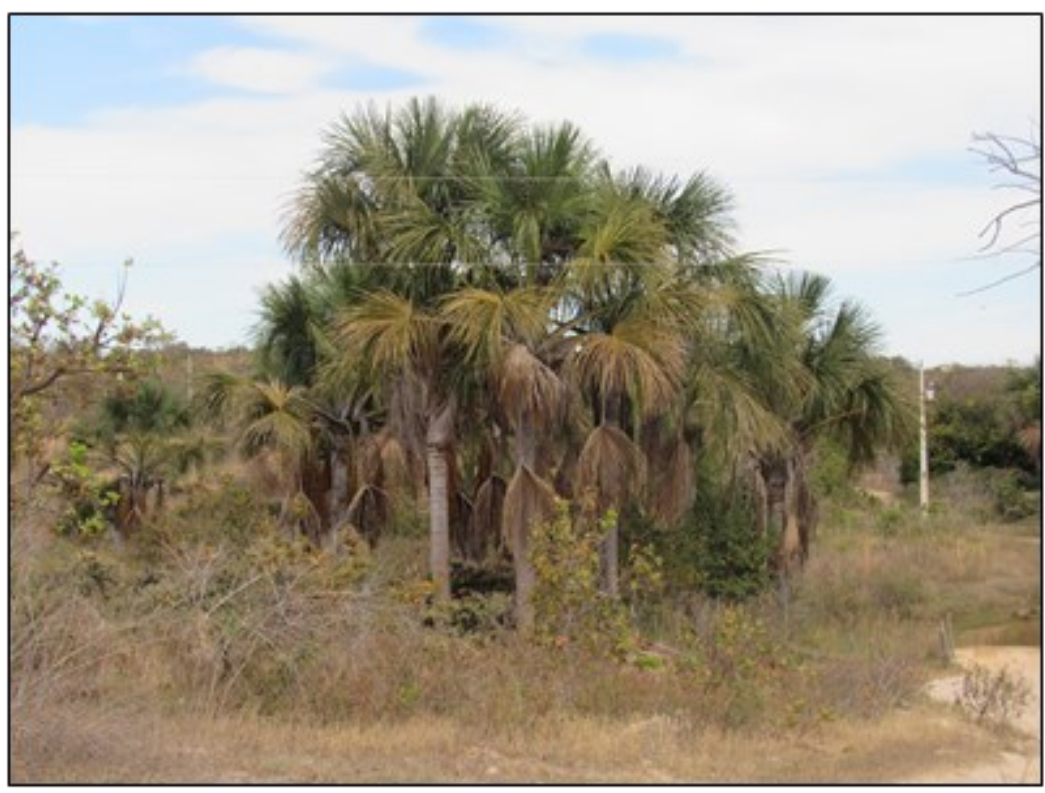

Fonte: INÁCIO, J.B.; SANTOS, R.J. (2019).

Conforme a estrutura arbóreo-arbustiva, o Cerrado no sentido restrito possui quatro categorias: Cerrado Denso, Cerrado Típico, Cerrado Ralo e Cerrado Rupestre. Além disso, existem quatro subtipos de palmeiras: Buritizal, Babaçual, Guerobal e Macaubal. (EMBRAPA, 2020).

As comunidades tradicionais que vivem na região Norte de Minas Gerais se denominam como geraizeiros, que segundo eles são áreas do Cerrado que estão nas chapadas, nos fundos de vale e veredas. Nos lugares estudados as falas dos sujeitos definem tais áreas com as mais úmidas e assim as mais importantes para o cultivo de alimentos.

Quanto as espécies de vegetação que encontramos nos gerais, são de árvores de médio e pequeno porte, além de algumas espécies mais ressecadas com galhos mais finos e o solo mais arenoso. Segundo relatos de moradores de veredas, trata-se de áreas que dificilmente seca e que não são atacadas pelo fogo. Mas, essa realidade vem sendo mudada, considerando que uma grande área de veredas que se encontra no território da RESEX, sofreu muito com as queimadas nos últimos dois anos, e sobretudo em 2020, onde houve uma grande incidência de queimadas no Cerrado.

Na região norte mineira há presença de outro bioma, a Caatinga. São áreas dos gerais que estão numa faixa de transição entre Cerrado e a Caatinga. No entanto, as espécies vegetais e animais que predominam consistem em características do Cerrado.

O contexto em que os geraizeiros estão inseridos envolvem situações de tensões fabricadas pelo interesse do agronegócio. Assim, a luta envolve a implementação da RESEX e o reconhecimento de seus modos de vida baseado em atividades extrativistas.

Para Nogueira (2009):

O plantio empresarial de eucalipto implicou em expropriação, grilagem de terras comunais e grande impacto ambiental, com a redução da oferta de água, frutos nativos, ervas medicinais e madeira - recursos estratégicos para e produção física e social dos Geraizeiros. Em aliança com sindicatos de trabalhadores rurais, entidades ligadas à Igreja Católica, Organizações Não Governamentais (ONGs) e redes socioambientais, como a Rede Cerrado, os Geraizeiros, hoje, reagem à violência sofrida, denunciam o caráter predatório do monocultivo de eucalipto e reivindicam o reconhecimento de seus direitos territoriais enquanto população tradicional. (NOGUEIRA, 2009, p.15).

Como tudo isso arrasta disputas territoriais, para permanecerem no lugar impõe criarem formas de obterem renda. Em alguns casos, por não conseguirem gerar a sua própria renda se submetem ao trabalho precarizado ofertado pelo agronegócio vinculado ao cultivo do eucalipto. Nesse caso, a condição para continuarem a luta é encarando como uma saída temporária e necessária para manter a família. 
Com o Cerrado "de pé", eles trabalham na coleta de frutos e em situações de fartura precisam estocar as poupas em geladeiras. Mas, estão demandando recursos financeiros para investirem em embalagens para armazenar os produtos, considerando que os mesmos serão vendidos em feiras abertas em eventos locais e regionais. Além dos problemas de armazenagem, de reconhecimento da qualidade de seus artigos existem outras dificuldades enfrentadas por esses sujeitos. Conforme a fala do entrevistado da comunidade Gerais do Calixto: "Uma das maiores dificuldades encontradas pelos geraizeiros é a falta de transporte, perda dos frutos e da área."

Cabe destacar que existe uma organização criada por iniciativa dos geraizeiros de Buritizeiro em parceria com o Movimento Graal Mulher ${ }^{3}$, que é a Chico Fulô, que possui essa denominação em homenagem ao Rio São Francisco e a flor do Cerrado representada em uma sua logomarca pelo pequi. (Figura 4). Essa organização tem por objetivo produzir as iguarias a partir dos frutos do Cerrado e trabalhar incentivando o crescimento da economia solidária, o que auxilia na geração de renda para os envolvidos no processo da coleta, de produção, divulgação até a sua comercialização.

Manter o modo de vida como extrativista depende de estrutura, de linhas de créditos subsidiados para que novas tecnologias possibilitem a geração de renda e trabalho. Assim, é dessas carências que alguns desses sujeitos precisam trabalhar no período de entre safra na construção de cercas em grandes propriedades que estão e serão ocupadas com plantações de eucalipto, carvoarias e nas propriedades onde é praticada a pecuária extensiva.

Figura 4 - Buritizeiro (MG): logomarca da Organização Chico Fulô (2019)

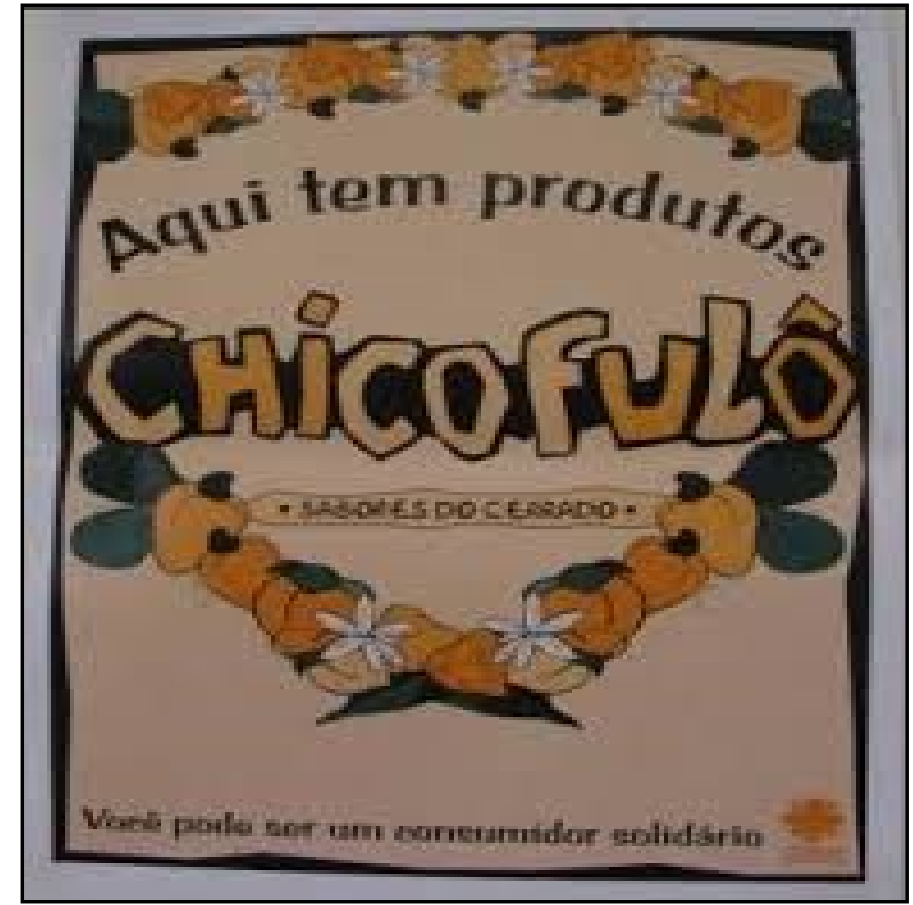

Fonte: INÁCIO, J.B.; SANTOS, R.J. (2019)

\footnotetext{
${ }^{3}$ É uma Organização Não Governamental que oferece cursos de capacitação, oficinas e atividades culturais à população do município. O Graal é um movimento que veio para o Brasil, no final da década de 1940, com sua primeira sede na cidade de São Paulo, e desde então foi se estendo para outros estados e regiões do Brasil, como Minas Gerais. Na década de 1970 foi aberta uma sede no município de Buritizeiro, que desde então, possui uma unidade que é coordenada e administrada por mulheres. Também faz parte do Fórum Mineiro de Economia Popular Solidária e possui representação no Conselho Municipal dos Direitos da Mulher. Além disso, atua no grupo focal da Rede Mulher e Educação e é sede da Secretaria Executiva da Rede Feminista de Saúde, regional do estado de Minas Gerais. Sem contar que possui status consultivo no Conselho Econômico e Social da ONU desde 1998. (Fonte: http://omovimentodograalnobrasil.blogspot.com/p/nossa-historia.html).
} 
Viver nestes lugares impõem improvisações e adaptações das populações tradicionais consideradas geraizeiras. A partir da sua condição socioterritorial é possível observar outras definições. Conhecê-las é importante para que possamos compreender sobre a realidade desses sujeitos, que são fundamentais historicamente e culturalmente para o Cerrado do Norte de Minas Gerais. De acordo com a definição apontada pela Secretaria do Estado de Direitos Humanos de Minas Gerais:

\begin{abstract}
Os gerais são como um grande quintal explorado e ocupado coletivamente, onde todos podem coletar frutos nativos e onde o gado é criado solto. Esses povos são famosos por seu conhecimento de plantas medicinais locais, e além do comércio de produtos oriundos das atividades de coleta, possuem pequenas lavouras, congregando assim as atividades agropecuárias e extrativistas. (Secretaria do Estado de Direitos Humanos, Participação Social e Cidadania - SDPAC, 2016, p. 26).
\end{abstract}

Os geraizeiros que fazem parte desse estudo ainda vivem na Comunidade Gerais do Calixto e Lança 1 (Figura 5). Mesmo sob tensão de diversos setores da sociedade eles conseguem coletar os frutos típicos do Cerrado como: (cagaita, buriti, mangaba, murici araticum, baru, coco catolé, umbu, jatobá, pequi), e produzirem poupas, doces, bombons e colher os frutos in natura para comercializar entre vizinhos e familiares. Trata-se de modos de vida singulares decorrentes de relações com a natureza.

Para Heidrich (2008, p. 285), "apesar de formas distintas de reprodução existentes, o universo tradicional é referencial não apenas da identidade, mas de como se conduz a vida, e o que possui valor simbólico".

Figura 5 - Buritizeiro (MG): Comunidades Tradicionais Gerais do Calixto e Lança 1, 2019

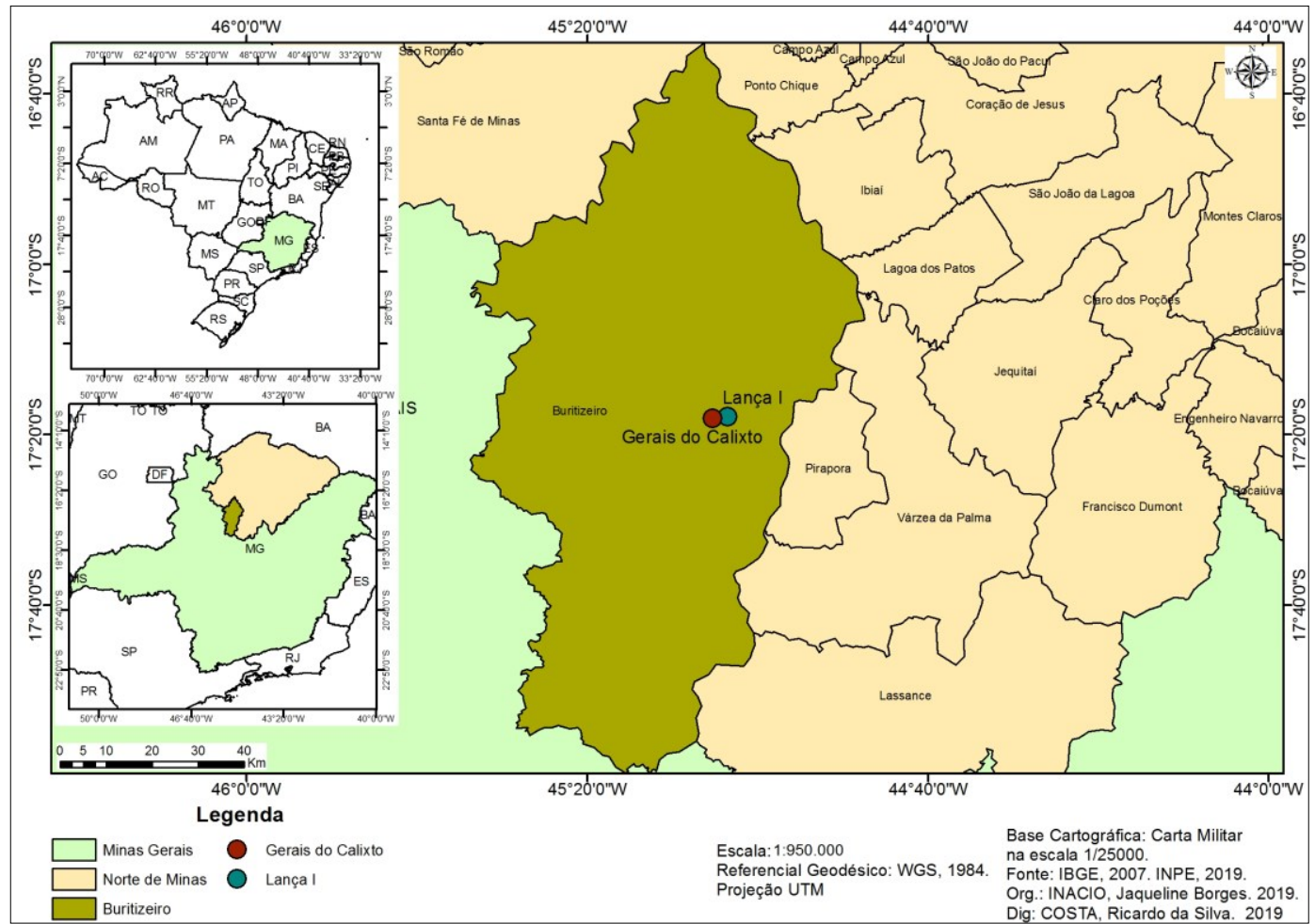

Fonte: IBGE, (2007). INPE, (2019). Org. INÁCIO, J.B. Dig. COSTA, R.S. (2019).

Esses sujeitos, por direito conquistado vão estabelecendo suas territorialidades na área requisitada para ser RESEX. Seus vínculos territoriais são estabelecidos em meio a conflitos e lutas, fazendo surgir estratégias de vida locais, contribuindo para proteção dessas áreas naturais. Além disso, nestas áreas, os grupos humanos criam e também recriam suas tradições e identidade.

Para Heidrich (2004, p. 31) "os vínculos territoriais são resultantes das ações ou práticas sociais de condução e representação da vida". A territorialidade se manifesta em todas as escalas espaciais e sociais; ela é consubstancial a todas as relações e seria possível dizer que, de certa forma é a 'face vivida' da 'face agida' do poder (RAFFESTIN, 1993). 
O poder do outro como presença efetiva comparece no entorno da área defendida para se tornar RESEX As propriedades que existem representam o poder hegemônico do capital. São produtivas, pois são ocupadas com plantações de eucalipto, gado e carvoarias. Presenças que prenunciam tensões, que desencadeiam conflitos na disputa por territórios.

As oposições podem ser percebidas a partir das diferentes lógicas sociais, inclusive de produção. Abordando as atividades, elas são díspares e ampliam desigualdades sociais. Contraditórios interesses disputam essas áreas diferentemente. Enquanto os geraizeiros usam a natureza disponível de forma consciente, os que estão a serviço do grande capital buscam o desenvolvimento das suas atividades econômicas sem considerar a importância de se preservar a sociobiodiversidade nos territórios das comunidades.

Neste processo estão envolvidos o meio biológico e os conhecimentos humanos de um determinado território. Para Porto-Gonçalves (2006, p.255):

A diversidade biológica proporciona uma complexificação das cadeias de reciprocidades que constituem as complexas cadeias tróficas por onde se dá o fluxo de matéria e energia no interior dos diferentes biomas e entre os diferentes biomas que constituem o sistema Terra. (PORTO-GONÇALVES, 20026, p.255).

A sociobiodiversidade neste contexto comparece como um processo dinâmico, apresentando múltiplas possibilidades de interação comunidade/bioma. No Cerrado brasileiro a sua biodiversidade, faz dele, a savana mais rica do planeta, possibilitando aos sujeitos que vivem nas comunidades tradicionais, existências densas de saberes e fazeres.

Além disso, os Geraizeiros vivem entrelaçados aos ciclos naturais do Cerrado. A partir de seus modos de vida constituíram comunidades que geraram estratégias de caráter múltiplo, nas quais, os usos da natureza, derivam de um conjunto de práticas sociais e culturais que pouco alteraram as paisagens daquelas áreas. Assim,

Estamos falando de grupos sociais que detêm expressões culturais próprias, um repertório considerável de mitos, ritos e conhecimentos herdados de ancestrais, ligados às atividades produtivas que, para além dos procedimentos técnicos e agronômicos envolvidos, garantem a produção, o consumo e uma maneira específica de se relacionar com a natureza e com o mundo. (Ministério Público de Minas Gerais- MPMG, 2012, p.14).

Cabe destacar que os povos que perderam parte de seus territórios, não deixaram de desenvolver as atividades de coleta dos frutos do Cerrado e comercializar seus artigos. Eles estabeleceram diálogos/negociações com aqueles que personificam o agronegócio e os proprietários de terra, para que possam entrar nas propriedades que ainda conservam parte do Cerrado, e fazer a coleta dos frutos, sem comprometer as outras atividades.

De acordo com Diegues (2000):

Essas comunidades tradicionais têm também uma representação simbólica desse espaço que lhes fornece os meios de subsistência, os meios de trabalho e produção e os meios de produzir os aspectos materiais das relações sociais, isto é, os que compõem a estrutura de uma sociedade (relações de parentesco etc.). A expulsão de suas terras implica a impossibilidade de continuar existindo como grupo portador de determinada cultura, de uma relação específica com o mundo natural domesticado. As populações tradicionais transferidas por força da criação de uma área natural de conservação exprimem esse desassossego de várias formas, também a sobre-exploração "ilegal" dos recursos naturais sobre os quais antes tinham domínio. (DIEGUES, 2000, p.65).

Nesta situação, eles vão criando maneiras de permanecer no lugar. Trata-se de conjuntos dinâmicos de estratégias de vida acionadas entre os sujeitos locais, lastreadas em suas territorialidades, as quais são constituídas coletivamente e comparecem nas práticas extrativistas deles como uso, domínio, identidade e pertença. Assim, explicita-se que as territorialidades derivam da dedicação de uma coletividade para ampliar o uso, dominando e se identificando profundamente com a coleta dos frutos do Cerrado em uma área explicitada pela experiência. Assim, aqueles sujeitos ao usarem o Cerrado para construírem formas de permanência além de se apropriarem daqueles elementos da natureza estão territorializando o espaço de vida deles. É, pois pelo uso, que aprendem a se colocar como pertencentes ao território. Na prática estão envolvidas relações de diversas ordens, inclusive de ressignificações de suas existências na relação com o Cerrado "de pé". 
Esses sujeitos são territorializados no processo que lhes permitem as suas territorialidades. Além do mais, o grupo está nessas áreas há gerações e seus modos de vida, saberes e fazeres não desaparecem nas tensões fabricadas pelo agronegócio. É necessário perceber o movimento naquilo que é reinventado para atender as suas necessidades e seus propósitos socioterritoriais.

O "ser" dos gerais pode ser classificado de duas maneiras distintas como: o "ser" de pertencer e fazer parte dos gerais. De tal modo, o lugar pertence ao sujeito assim como o sujeito pertence ao lugar. $\mathrm{E}$ temos o "ser" dos gerais enquanto humano, cheio de sentimentos e vontades que são inerentes ao ser independente da condição em que vivem. (INÁCIO, 2014, p.134).

De acordo com Carlos (2007):

O lugar é produto das relações humanas, entre homem e natureza, tecido por relações sociais que se realizam no plano do vivido, o que garante a construção de uma rede de significados e sentidos que são tecidos pela história e cultura civilizadora produzindo a identidade, posto que é aí que o homem se reconhece porque é o lugar da vida. O sujeito pertence ao lugar como esse a ele, pois a produção do lugar liga-se indissociavelmente à produção da vida. (CARLOS, 2007, p. 19).

A permanência no território envolve lutas por direitos territoriais. Elas estão implicadas na defesa do meio ambiente, bem como, de colher, produzir e comercializar os frutos do Cerrado e seus derivados. Manter o Cerrado "de pé" decorre do poder de suas territorialidades e também da ação criativa e que redefine as relações sociais no grupo social, na comunidade e entre familiares. Assim, particularmente em relação a:

[...] a conformação da família nesses contextos atende a necessidades morais, sociais, culturais e econômicas próprias, sobretudo porque a família é central na organização de toda a vida da comunidade. Não devemos separar família de território, pois em grande medida um território se constrói a partir da aglutinação de vários sítios familiares e de uma ancestralidade comum. (Ministério Público de Minas Gerais - MPMG, 2012, p. 13).

Sendo assim, ao preservar o território acionam as suas territorialidades fazendo comparecer jeitos de ressaltarem seus valores humanos, costumes, modos de vida imbricados a comunidade a que pertencem.

Nas áreas destinadas ao extrativismo, os povos tradicionais não estão livres das tensões procedentes de uma permanente demanda por recursos naturais. O ideal seria que o Estado agisse criando políticas públicas em prol das demandas locais, que fossem executadas de forma transparente e democrática. Mas, diante do atual contexto político, compreendemos que os governantes, estão priorizando as demandas do mercado capitalista, oferecendo cada vez mais subsídios para que o agronegócio e os grandes empreendimentos como as usinas hidroelétricas avancem sobre territórios ocupados por populações tradicionais e indígenas.

Sendo assim, os povos tradicionais buscam reunir-se em conselhos comunitários, movimentos sociais, ONGs, instituições que os auxiliem na luta pela permanência no lugar, bem como, por desenvolvimento de suas atividades, pois, os recursos disponíveis não podem ser explorados a partir de uma única lógica social.

No ano de 2006 foram feitos levantamentos por uma equipe de pesquisadores do Centro de Referência em Conservação da Natureza e Recuperação de Áreas Degradadas (CRAD) da Universidade de Brasília (UNB), das espécies vegetais nativas do Cerrado no município de Buritizeiro e Ibiaí, a fim, de obter dados para a implementação de duas Unidades de Conservação de Uso Sustentável, sendo classificadas como Reservas Extrativistas.

A proposta de criação das RESEX, surgiu das demandas das populações tradicionais do Norte de Minas Gerais. Foram catalogadas mais de 200 espécies de vegetação nativa no local, sendo que nem todas são utilizadas pelos geraizeiros, considerando que eles fazem o uso de árvores frutíferas e medicinais

A proposta inicial de criação destas Unidades de Conservação de Uso Sustentável consiste na conservação dos recursos naturais e para que as comunidades locais tenham segurança fundiária, acesso a linhas de crédito e financiamento para a reforma agrária, fomento comercial, proteção e reconhecimento do seu modo de vida. (Ministério do Meio Ambiente-MMA). Porém, é importante destacar que no atual contexto político em que o Brasil está inserido, essas garantias de proteção das UCs, estão sofrendo ameaças, considerando que as novas estratégias governamentais é de ampliar cada vez mais as atividades de exploração dos recursos naturais. 
Em 2007 foi delimitada essa área para criação da RESEX intitulada Serra do Alemão, que dá nome a serra que se encontra na região dos Gerais. A área total é de 33.000 hectares, com 20.000 hectares utilizados para coleta dos frutos e 800 hectares de área de conflito.

No entanto, ainda não foi regularizada pelo Ministério do Meio Ambiente, e as populações tradicionais do município continuam na luta para que seja decretada a institucionalização dessa Unidade de Conservação de Uso Sustentável.

Aquela RESEX se confirmada pode ser uma fonte de geração de trabalho, renda e dignidade humana para os povos tradicionais e também pode ser uma alternativa de inclusão de outras pessoas, pois:

Normalmente esses povos e comunidades possuem práticas tradicionais, vínculos territoriais e de parentesco, marcas de identidade próprias, lutas políticas pela recuperação de territórios ou pela manutenção de seus modos de vida, luta pela ampliação e efetivação dos seus direitos. (Ministério Público de Minas Gerais MPMG, 2012, p. 15).

A legitimação de território é urgente, os aspectos socioculturais serão valorizados e também estarão contribuindo com a preservação e conservação da sociobiodiversidade. Na vida prática:

[...] A gente coleta os frutos de forma consciente, retira o necessário para fazer os produtos como: doces, licores, picolés e polpas, e deixa uma parte para os bichos alimentar. Nós acabamos é ajudando a natureza, porque a gente não acaba com tudo, nem derruba as árvores[...]. ${ }^{4}$

O modo de vida comparece na relação com a natureza. A partir do cotidiano também se explicam os vínculos territoriais e as relações sociais tecidas no lugar. Essas relações que possibilitam a permanência dos geraizeiros ou "remanescentes" no lugar estão enraizadas na vida desses sujeitos (INÁCIO, 2014).

\section{CONSIDERAÇÕES FINAIS}

A luta em defesa do território é repleta de estratégias sociais, resultando em identidades e pertenças ao território. O uso da RESEX pelos geraizeiros, além de ser uma forma de r-existência é neste território que eles desenvolvem seus conhecimentos necessários para poderem ampliar suas atividades e garantirem a vida em suas várias dimensões.

Os geraizeiros que vivem na área reivindicada para abrigar a RESEX de Buritizeiro, lutam pelo direito de usar o território, além do direito de plantar, pescar, cultivar e colher alimentos. Trata-se de defender suas práticas socioculturais criadas e recriadas a partir de relações de convivência com suas famílias e a comunidade.

Assim, ao preservar o Cerrado "de pé", propõem formas singulares de uso para o território. A partir dessas práticas eles manifestam suas territorialidades, fazem comparecer na relação com a sociedade os seus valores humanos, costumes, modos de vida tradicionais dentro das comunidades em que vivem.

Suas estratégias de vida incluem formas de permanências. Elas são dinâmicas e decorrem de práticas sociais densas e complexas, capazes de desenvolver táticas de ampliação e diversificação das suas atividades. Nesse sentido, é fundamental a participação do Estado e a de outras instituições, para viverem a partir do extrativismo e dos conteúdos do Cerrado.

Portanto, é preciso quebrar o paradigma de que as Unidades de Conservação de Uso Sustentável devem ser intocadas sem que os povos tradicionais que já vivem nessas áreas possam utilizar de forma consciente os recursos disponíveis nesses lugares.

\section{AGRADECIMENTOS}

Agradecemos a Coordenação de Aperfeiçoamento de Nível de Pessoal (CAPES), pelo financiamento desta pesquisa de doutorado.

\footnotetext{
${ }^{4}$ Entrevista realizada em trabalho de campo no município de Buritizeiro-MG, em agosto de 2019.
} 


\section{REFERÊNCIAS:}

BRASIL. Ministério do Meio Ambiente. Estudos podem ajudar na criação de reservas extrativistas no norte de Minas Gerais. 2011. Disponível em: https://www.mma.gov.br/informma/item/6990estudos-podem-ajudar-na-criacao-de-reservas-extrativistas-no-norte-de-mg . Acesso em: 20 de janeiro de 2020.

BRASIL. CNPCT - Comissão Nacional de Desenvolvimento Sustentável dos Povos e Comunidades Tradicionais. Portal Ypadê. Ministério do Meio Ambiente. Geraizeiros, 2016. Disponível em: http://portalypade.mma.gov.br/geraizeiros. Acesso em: 28 de setembro de 2020.

CARLOS, A. F. A. O lugar no/do mundo. Edição eletrônica: LABUR. São Paulo, 2007.

Cartilha Direitos dos Povos e Comunidades Tradicionais Política Estadual para o Desenvolvimento Sustentável dos Povos e Comunidades Tradicionais de Minas Gerais.

Coordenadoria de Inclusão e Mobilização Sociais (CIMOS). Ministério Público de Minas GeraisMPMG, 2012.Disponível em: https://conflitosambientaismg.lcc.ufmg.br/wpcontent/uploads/2014/04/Cartilha-Povos-tradicionais.pdf.Acesso em: 18 de janeiro de 2020.

Coleção Cadernos de Direitos Humanos: Cadernos Pedagógicos da Escola de Formação em Direitos Humanos de Minas Gerais | EFDH-MG. Direitos Humanos e Cidadania - Proteção, Promoção e Reparação dos Direitos das Comunidades Tradicionais. Vol.13. Rogerio Duarte do Pateo. Belo Horizonte: Marginália Comunicação, 2016. Disponível em:

http://www.direitoshumanos.mg.gov.br/sites/default/files/documentos/geral/livro_13_comunidades_tradicio nais.pdf. Acesso em: 06 de março de 2019.

DIEGUES, C. 0 mito moderno da natureza intocada. 3. ed. São Paulo: Hucitec Núcleo de Apoio à Pesquisa sobre Populações Humanas e Áreas Úmidas Brasileiras, USP, 2000, p. 161.

EMBRAPA- Empresa Brasileira de Pesquisa Agropecuária. Bioma Cerrado. Disponível em:https://www.embrapa.br/cerrados/colecao-entomologica/bioma-cerrado. Acesso em: 14 de setembro de 2020.

GAMA, Maria das Graças Campolina Cunha. Água, Vereda, Veredeiro: Um estudo sobre as agriculturas camponesa e comercial município de Buritizeiro-MG. 119 f. Dissertação (Mestrado em Geografia) Programa de Pós-Graduação em Geografia da Universidade Federal de Uberlândia.2006.

HEIDRICH, A. L. Conflitos territoriais na estratégia de preservação da natureza. (Org.) SAQUET, M.A.; SPOSITO, Eliseu Savério. In: Territórios e territorialidades: teorias, processos e conflitos. 1 ed. São Paulo: Expressão Popular: UNESP. Programa de Pós-Graduação em Geografia, 2008, p.271-290.

INÁCIO, J.B. Contradições e tensões no processo de expansão do setor sucroenergético em Iturama MG. 157 f. Dissertação (Mestrado em Geografia) Programa de Pós-Graduação em Geografia da Universidade Federal de Uberlândia. 2014.

MINAS GERAIS. Ministério Público de Minas Gerais-MPMG, 2012. Cartilha Direitos dos Povos e Comunidades Tradicionais Política Estadual para o Desenvolvimento Sustentável dos Povos e Comunidades Tradicionais de Minas Gerais. Coordenadoria de Inclusão e Mobilização Sociais (CIMOS). Disponível em:https://conflitosambientaismg.lcc.ufmg.br/wp-content/uploads/2014/04/CartilhaPovos-tradicionais.pdf. Acesso em: 21 de janeiro de 2020.

O Movimento Graal no Brasil. Nossa história. Disponível em: http://omovimentodograalnobrasil.blogspot.com/p/nossa-historia.html. Acesso em: set.2020.

NOGUEIRA, Mônica Celeida, R. Gerais a dentro e a fora: identidade e territorialidade entre Geraizeiros do Norte de Minas Gerais. 233 f. Tese (Doutorado em Antropologia). Programa de Pós-Graduação em Antropologia Social da Universidade de Brasília. 2009.

PORTO GONÇALVES, Carlos Walter. A globalização da natureza e a natureza da globalização. Rio de Janeiro: Civilização Brasileira, 2006.

RAFFESTIN, Claude. Por uma geografia do poder. São Paulo: Editora Ática. 1993.

Recebido em: 20/09/2020

Aceito para publicação em: 19/11/2020 